\title{
Proyecto Hidroaysén: capitalismo extractivista, regulación estatal y acción colectiva en la Patagonia
}

\author{
Sonia E. Reyes Herrera \\ Universidad de Valparaíso, Chile. \\ Email: sonia.reyes@uv.cl \\ Juan Carlos Rodríguez Torrent \\ Universidad de Valparaíso, Chile. \\ Email: juancarlosrodriguezt@yahoo.com
}

\begin{abstract}
Resumen: En este artículo entendemos que el eje de los conflictos ambientales en general, y en la Patagonia en particular, está definido por la forma específica de producción del territorio. Es decir, sobre el uso de los activos naturales, las relaciones que se establecen con la naturaleza, las formas de gobernar estos territorios (actores) y cuál es la relación que mantienen con otros. La emergencia de este tipo de conflictos se explica por la expansión del capitalismo extractivista en zonas de frontera y por la escasa presencia del Estado a nivel local, en términos de provisión de servicios y de una débil regulación en materia ambiental que acaba favoreciendo intereses territorialmente exógenos y contrarios a los endógenos. Frente al anuncio de la construcción de cinco centrales hidroeléctricas en la región de Aysén-Chile, en este artículo se analiza la acción de los tres principales actores: Comunidad, Estado y empresa privada, que interactúan durante el proceso de discusión y aprobación del megaproyecto Hidroaysén, proponiendo escenarios territoriales desde racionalidades diferentes, que definen modelos de desarrollo contradictorios para una bioregión.
\end{abstract}

Palabras clave: Patagonia, capitalismo extractivista, conflictos ambientales, acción colectiva.

\section{Hidroaysén energy project: extractive capitalism, state regulation and collective action in Patagonia}

\begin{abstract}
In this article we understand that the axis of environmental conflicts in general and on Patagonia in particular, is defined by the specific form of production planning, in other words: the use of natural assets, the relationships established with nature, forms of government in these territories (actors) and their relationship they establish with others. The emergence of this type of conflict is explained by the expansion of extractive capitalism in border areas and the limited presence of the state at local level, in terms of service delivery and weak environmental regulation which ends favoring exogenous interests, in opposition to endogenous ones. On the face of the announcement of the construction of five hydroelectric plants in the Aysen region, in this paper we analyze the action of the three main actors: Community, State, and private enterprise, who interact during the process of discussion and approval of the Hidroaysén megaproject, proposing each actor
\end{abstract}


scenarios based on different rationalities which define contradictory development models for a bioregion.

Keywords: Patagonia, extractive capitalism, environmental conflicts, collective action.

\section{Projeto Hidroaysén: capitalismo extrativista, regulação estatal e ação coletiva na Patagônia}

Resumo: Neste artigo, vamos entender que o eixo dos conflitos ambientais em geral, e na Patagônia em particular, se encontra definido pela forma específica de produção do território. Ou seja, sobre a utilização dos recursos naturais, as relações estabelecidas com a natureza, as formas de governar estes territórios (atores) e qual a sua relação com os outros. O surgimento deste tipo de conflitos é explicado pela expansão do capitalismo extrativista em zonas de fronteira e pela escassa presença do Estado no âmbito local, em termos de prestação de serviços e de uma fraca regulação ambiental que acaba favorecendo apenas a interesses territorialmente externos e contrariamente aos endógenos Considerando-se o anúncio da construção de cinco usinas hidrelétricas na região de Aysén-Chile, este artigo analisa a ação dos três principais atores: Comunidade, Estado e empresas privadas que interagem durante o processo de discussão e aprovação do megaprojeto Hidroaysén, propondo cenários territoriais desde diferentes racionalidades, que definem os modelos de desenvolvimento conflitantes para uma bioregião.

Palavras-chave: Patagônia, capitalismo extrativista, conflitos ambientais, ação coletiva.

$* * *$

\section{Introducción $^{1}$}

Las transformaciones en la economía mundial en el último cuarto del siglo pasado y la implementación del neo extractivismo, como modelo de explotación de recursos primarios sin participación del Estado como fue en el tipo convencional, han reubicado a América Latina con sus activos territoriales, naturales y sociales como oferente en el mapa de la geopolítica mundial. La valorización de sus bienes energéticos, mineros, madereros, agrícola/acuícola e hídricos, convertidos en mercancías circulan por el mercado global. Este "metatipo de experiencia capitalista monocultural angloamericano” o de “composición uniforme” (Brandão, 2009: 43) se enfrenta con experiencias de vida social y estructuras institucionales locales que son esencialmente plurales y en muchos casos renuentes a grandes cambios.

El proceso, muy claro en Chile en relación al agua y la minería, ámbito donde se reafirma la condición de capitalismo dependiente que configura los marcos de una expropiación ecoterritorial extensiva e intensiva, sin distingos de población ni especialización productiva como son pequeños productores, campesinos, comunidades pastoriles y grupos étnicos-, requiere también de acumulación de poder político y una complicidad bajo la máxima del crecimiento para el desarrollo; una marginalización estructural 
de grandes sectores de la población por parte de intereses financieros, corporativos y empresariales. Se trata de una nueva acumulación, por “desposesión” (Harvey 2004); hay una apropiación de la naturaleza, una posesión de nuevos activos a costo cero que permiten la reproducción del capital, como ocurre con los derechos de agua en la ley chilena: el recurso es un bien de uso público y también de uso económico (Larraín 2013; Sohr 2012; Yáñez y Molina 2011).

De tal forma, la ejecución de los emprendimientos provoca, irremediablemente, alteraciones significativas a nivel territorial y en la vida de las poblaciones locales, a partir de nuevas infraestructuras viales, ferroviarias, portuarias y aéreas conforme al modelo IIRSA ${ }^{2}$, en las poblaciones como modelos de agregación urbana y reconversión productiva, y en la naturaleza como pasivos o impactos difíciles de prever para las distintas especies y sus ecosistemas. Asimismo, y como cuestión fundamental: sin unas condiciones de Estado, que entregue garantía y resguardo de la inversión, y que posibiliten la entrada del capital y las seguridades de rentabilidad.

Más allá de las dimensiones de las transformaciones, que en muchos casos sólo implican especulación monetaria y rentismo, y de cómo se ha consumado en términos multilaterales la nueva posición productiva del continente y de Chile, es importante observar cómo se expresan las acciones y relaciones de actores como el Estado, la empresa privada y las organizaciones sociales en términos territoriales, ya que esta condición estructural ha venido generando una importante disconformidad social, centrando su discurso en el "crecimiento" y la "eficiencia”, pero sin un debate ideológico que supere los márgenes de la economía.

En el país, el malestar contra este modelo se traduce en: 1) la gran concentración de recursos y posibilidades en Santiago, la capital, en la que vive más del 40\% de la población; 2) la condición de déficit por falta de agenciamiento del Estado en las regiones del extremo norte y sur del país; 3) el sentido de desprotección por la ausencia de un modelo de derechos garantizados de acceso a la salud, la educación y las pensiones; 4) que las grandes empresas tributan poco a nada, a cambio de grandes ganancias; $y$, 5) los pasivos ambientales que deja el modelo neo extractivista y la creciente carbonización de la matriz energética. Lo anterior genera una condición desigual en términos territoriales, de concentración de oportunidades y servicios, y conlleva a la existencia de regiones ganadoras y perdedoras, distribución desigual de riesgos e incertidumbres, y de localidades y zonas que pueden ser sacrificadas social y ambientalmente, a pesar que algunas como Aysén sea definida como “reserva de vida”.

Paralelamente a este malestar, Chile enfrenta un gran desafío. Su economía basada en una reducida canasta de exportación (70\% de cobre), no cuenta con petróleo ni carbón de calidad. Esta condición es esencial para su modelo de desarrollo, sin precios competitivos de las fuentes energéticas es inviable y se hipoteca su futuro (Sohr 2013). La cuestión de su debilidad no es reciente; el problema estructural deriva de los años 70 con 
el término del petróleo barato, vivimos permanentemente en un régimen de escasas lluvias y sequía para la generación hidroeléctrica; el cambio climático nos afecta severamente y que las propuestas y discusiones para el desarrollo de energías no convencionales es reciente.

La dependencia externa de la matriz energética, es sólo entendible si se observa la ausencia de un proyecto nacionalista y de industrialización por parte de los militares chilenos durante los años de dictadura (19731989). Éstos, no sólo quitaron al Estado sus atribuciones como regulador, ordenador y direccionador para la generación de políticas públicas, sino que entregaron a los economistas formados en Chicago el diseño de las políticas que convirtieron a Chile en el país económicamente más liberal del continente y menos regulado, y también con el futuro más abierto. A diferencia de Brasil, donde también hubo una larga dictadura militar de derecha (1964-1985) que industrializó y generó una política energética de largo plazo, previendo su vulnerabilidad, Chile estuvo y está al servicio de los grandes grupos económicos, con escasa planificación, y no impulsó de la mano del Estado iniciativas de generación energética no convencionales (ERNC); y, más tarde, no ha tenido condiciones políticas de aceptación ciudadana para implementar una que permita sustentabilidad y seguridad de abastecimiento en el largo plazo, para viabilizar su modelo de exportaciones (Sohr 2013).

Estas condiciones políticas refieren principalmente a la falsa oposición entre Estado y mercado, a cuestiones de ordenamiento territorial, y los bemoles ante la posibilidad de explorar la opción de la energía nuclear, dónde ubicar plantas de generación de energía termoeléctrica y construir mega centrales hidroeléctricas, ya que una decisión o “autorización” a privados significa un largo proceso de negociación y judicialización con las comunidades afectadas por el emplazamiento. Éstas, alertas ante los anuncios, se (re)apropian de sus territorios y se organizan en torno a su defensa. El caso de mayor visibilidad, de permanencia en el tiempo, y de intensidad en términos de su negociación y figuración de actores, se ha centrado en el proyecto hidroeléctrico Hidroaysén.

En términos técnicos, el proyecto Hidroaysén consiste en la construcción de dos represas en el río Baker (el más caudaloso de Chile) y tres en el río Pascua, y una línea de trasmisión de 2.300 km, que tendrían una producción de 2.750 Mega Watts. Un dato no menor para comprender las relaciones entre el Estado y el capital, será que “entre enero y marzo de 1990, Endesa recibió gratuitamente y a perpetuidad los derechos de agua de los ríos Ibáñez, Pascua y Baker. Posteriormente, en 1999, el presidente Eduardo Frei Ruiz-Tagle asignó recursos públicos para la realización sobre el potencial hidroeléctrico de estos ríos, allanando el camino para la formulación de megaproyectos energéticos para la región” (Sohr 2012: 88).

En lo económico, el proyecto significa una inversión inicial de USS 5.000.000, en la construcción de las presas y unos USS 3.000 .000 en el levantamiento de unas 6.000 torres de alta tensión, de entre 60 y 70 metros. 
En lo territorial, afectaría a la región más prístina del país, sin que prácticamente una gota de energía se quede en la región, destinándose su producción a satisfacer principalmente la demanda de la gran minería del cobre en el norte del país. En lo ambiental, pasará por paisajes lacustres y bosques, por 16 áreas protegidas por el Estado y 32 de particulares. En lo político, constituye una decisión que los últimos tres gobiernos han sido incapaces de decidir y los recientes candidatos presidenciales (2013) fueron ambiguos en sus opciones, por lo antipopular de una medida en su favor. En lo comunicacional, la iniciativa ha superado el espacio local, regional y nacional, posicionándose a nivel mundial y transformada como bandera de lucha de movimientos ambientalistas de carácter mundial como Greenpeace. Además, ha sido definido como un acto predatorio e irracional en la revista Nature: "Se aprueban gigantes represas en Chile" (2011) y en una editorial del New York Times titulada “Keep Chilean Patagonia Wild” (2011).

\section{Lugares de emplazamientos de las represas en la región de Aysén}

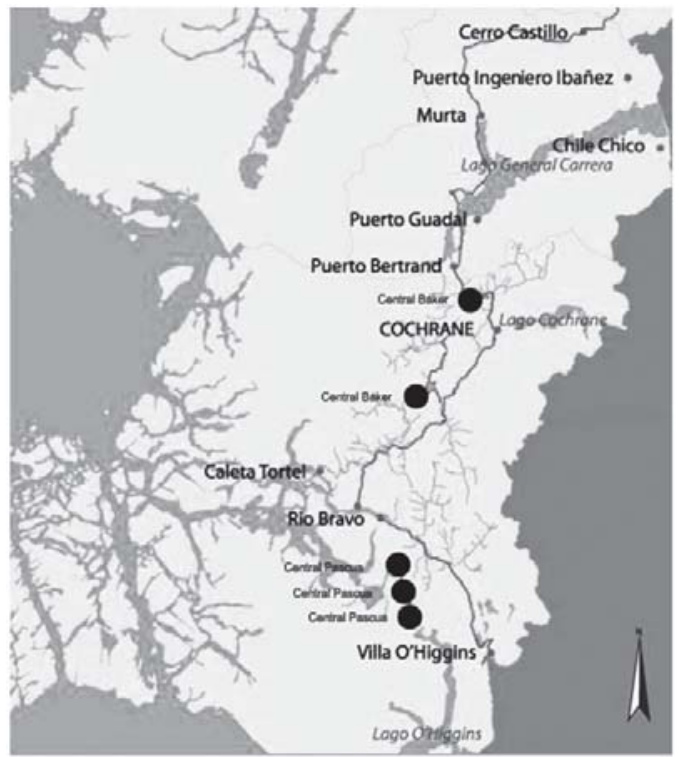

Fuente: elaboración propia.

El emplazamiento se ubicaría en la Patagonia, la que se extiende desde el Estuario de Reloncaví, en la Comuna de Hualaihué hasta la Tierra del Fuego, incluyendo 8 provincias y 24 comunas. Su extensión es de 265.275,8 km2 y 275.218 habitantes (INE 2012), y geográficamente es considerado uno de los lugares de más difícil accesibilidad del continente, la última frontera del país y del capitalismo, e identifica en la actualidad a la figura 
mítica de El Dorado. La Patagonia también ha sido definida como una "geomarca verde", que activa un imaginario con atributos positivos y deseables, ya que existe una hipervaloración de su paisaje(Medina, Rodríguez y Reyes 2013), integrándose de esa forma el capital natural de la región como uno de los centros del turismo del capital global.

El año 2011 ha sido considerado por distintos analistas emblemático para el país, ya que al margen de los partidos políticos la ciudadanía salió a las calles a protestar, con una mezcla de racionalidad y emocionalidad, contra un modelo económico predatorio de la riqueza y la naturaleza, expropiatorio de derechos territoriales y culturales (INDH 2012), y precario en seguridad social. En distintos lugares se instaló la protesta estudiantil, el rechazo a la construcción de las represas del megaproyecto Hidroaysén, el bloqueo de la ciudad de Punta Arenas por el alza en el valor del gas para uso domiciliario, el abandono de la región y la concentración de recursos en la capital. La lista del malestar se extiende de norte a sur con distintos epicentros, y con protestas étnicas contra el Estado y multinacionales, y frente a impactos ambientales nocivos para la salud y lesivos para comunidades de economías especializadas (INDH 2012).

En mayo de 2011, una masiva manifestación en Santiago (y en las principales capitales regionales del país) reunió a cerca de 30 mil personas que se manifestaron contra la aprobación del proyecto Hidroaysén, si bien pueda parecer una manifestación “espontánea”, se inscribe en un proceso de organización y defensa del medio ambiente que se viene desarrollando en los últimos 20 años en el país y en los nueve más recientes en la región de Aysén. Éste adquiere visibilidad en los medios de comunicación, y se caracteriza por la mayor articulación y formación de redes entre las diferentes organizaciones sociales, para confrontar directamente las agendas estales y privadas. Así, se observa una ciudadanía cada día más opositora a la construcción de grandes proyectos de infraestructura, minería y otros rubros que portan amenazas a sus comunidades y que en la elaboración de sus marcos de acción vinculan sus problemáticas con los temas medioambientales a nivel global (Bowen, Fabrega y Medel2011; Bebbington 2007; Svampa 2011; Machado 2011; Sabatini y Geisse 2010; Antonelli 2010).

En las páginas siguientes consideramos el proyecto Hidroaysén como paradigmático del modelo y la acción colectiva como un caso emblemático por la adhesión alcanzada, los recursos desplegados y los resultados obtenidos. Tratamos de relevar y analizar la trayectoria del conflicto y sus principales hitos a través del movimiento social Patagonia Sin Represas, como contraparte y principal opositor al megaproyecto, de tal forma se destacan las características de una acción colectiva sostenida en el tiempo contra una empresa multinacional.

El análisis de información de prensa nacional e internacional, más las notas y registros de campo dentro de un programa de investigación sobre estudios territoriales en la Patagonia son la principales fuentes de datos del trabajo. A partir de ello, se sustenta que el resultado de la apropiación social 
del espacio y de su contenido, es el momento donde juegan un papel fundamental los procesos de construcción de las identidades territoriales que permiten la organización y estructuración social, el surgimiento de acuerdos y normas que posibilitan la negociación a escala territorial.

En la primera parte, se presenta una discusión conceptual en torno a la relación capital-naturaleza, como marco de referencia general. En la segunda, se representan las diversas estrategias desarrolladas por el movimiento social en oposición a la construcción de las represas y su tendido eléctrico. En la tercera, la cuestionable relación entre el Estado y el bien público y la prevalencia de lo privado.

\section{Discusión conceptual: la relación capital-naturaleza}

Entendemos el problema socio ambiental en la perspectiva de la ecología política y en su intersección con la economía política, como espacio fundacional; como un esfuerzo por comprender las dinámicas existentes detrás de los problemas ambientales; y, como el campo de análisis y de reflexión común a distintas disciplinas (Bebbington 2007) que produce, da forma y explica las relaciones de uso y usurpación de territorios y recursos, en los marcos de un modelo extractivista exportador, que expresa una condición singular que podemos denominar como glocal, híbrida o de co-producción de lo local (Bebbington 2007; Svampa 2008; Gudynas 2009; Alimonda 2011). Modelo que demanda una explotación y transformación intensa del entorno natural y social, con alteración de los activos naturales relacionados con las estrategias de uso y efectos diversos y desiguales en las poblaciones locales, con acciones e interacciones entre actores que generan nuevos territorios (Tetreault 2008; Bebbington 2007). Esto, se traduce en desigualdades regional, porque "la división internacional del trabajo no es sólo de división social del trabajo, sino igualmente una división global de la naturaleza” (Lamberti 2011: 305).

El campo de análisis de la ecología política y la economía política revela el conflicto entre geografías, es decir, concepciones de uso plural o de hegemonía de un actor sobre otro(s) en la definición territorial, las subalternidades territoriales como expresión de un colonialismo interno y de la infra o supervaloración de recursos de una eco-región (bio-región) por parte del capital; también se encuentra "relacionada a las modalidades y sofisticación científico-tecnológicas alcanzadas, incluyendo el ritmo y dimensiones de su operación” (Delgado 2013:10).

En este sentido, reconocemos que desde hace más de tres décadas autores como Martínez- Alier habla de los problemas ecológicos desigualmente distribuidos; Arturo Escobar, incorpora la figura estructural de la memoria histórica del conflicto ambiental; Víctor Manuel Toledo, relaciona los estudios rurales y los de etnoecología con las propuestas de desarrollo y el ordenamiento territorial; Enrique Leff, enfatiza en las relaciones de poder, las distintas racionalidades, saberes y haceres intervinientes que 
cruzan el conflicto ambiental; Héctor Alimonda, recuperando la figura del colonialismo, explora el campo desde las articulaciones complejas y contradictorias de prácticas y representaciones que hunden sus raíces en la posición subordinada del continente, pero también luego desarrollada por los Estados nacionales (Martínez-Alier 2003; Escobar 2011; Toledo 2008; Leff 2006; Alimonda 2011).

Estos y otros autores, apuntan a definir los problemas derivados del modo de apropiación de la naturaleza como propios de la incorporación de los territorios al sistema económico mundial, a la ampliación de las fronteras y la expropiación de nuevos; y, con matices, se plantean como objetivos explicar, explorar y sintetizar los conflictos de raíz histórica, devenidos del valor de los recursos, los modos de apropiación, las narrativas, el poder y las prácticas. Por tanto, se trata de la influencia y subordinación que produce territorio, propias de las relaciones sociales y productivas en diferentes escalas espaciales y temporales. En términos de Anthony Bebbington: "las localidades y territorios no existen por sí mismos, sino son productos de las dinámicas capitalistas, las historias locales y las formas en que distintos actores sociales (locales o no) trabajan, negocian y dan sentido a estos procesos", para lo que reconoce tres campos: el de la resistencia y protesta; de la gobernanza formal; y del desarrollo del capitalismo (Bebbington 2007: 33-35).

Como apreciaremos en las páginas siguientes, la cuestión es compleja en términos de racionalidades e imaginarios, ya que al centro está el Estado y su política exportadora de recursos primarios y la imagen casi perenne de la existencia de tierras baldías o mal aprovechadas en la Patagonia; la empresa, que busca la ampliación de sus negocios; y, las comunidades que resienten sus derechos, especialmente el de decidir sobre su territorio. En este sentido, hay una delgada línea entre desarrollo, expansión de las fronteras productivas y democracia, por lo que ningún proceso ambiental puede observarse solo en términos locales y ambientales.

Desde el punto de vista económico y territorial, frente a la diferenciación de los activos regionales y la interrelación y dependencia de las áreas, con recursos desigualmente distribuidos e imperfectamente móviles como en el caso de la energía (centro sur) y la minería (norte), el Estado de Chile es incapaz de responder qué sucedería en el país frente a una crisis energética internacional, ya que depende en un $70 \%$ de un suministro externo. Por tanto, se ha ido revelando no sólo la ausencia de una política energética, sino una falta de política de ordenamiento territorial y déficit importante en términos de política ambiental. Esto significa que, sobre los distintos territorios se ha incorporado la variable incertidumbre como condición, la que es vivenciada y producida simultáneamente como dispositivos de poder y control social. De modo que, es importante consignar en el análisis territorial quiénes la vivencian, quiénes la producen y quiénes la hacen circular (Tobío 2012:13). 
De este modo, claramente existen dos planos analíticos que son importantes de relevar: a) el acceso a los recursos, referido a la gestión de los mismos, su distribución y circulación; b) la gestión del territorio, como propuesta de corto o largo plazo, y de gestión pública o privada. En estos términos, los problemas observados son de legitimidad de las opciones, de colaboración, de conflicto y de resistencias sociales, porque las vidas de las personas se encuentran intrincadas y se entretejen con relaciones que a veces están más allá de su entorno inmediato, ya que son propias de la globalización y el neoliberalismo. Así, el agua, los monocultivos, los recursos mineros y forestales, los ecosistemas, las áreas protegidas, las reservas de la biosfera y los territorios étnicos entran a la disputa. Por ello, nos parece importante relevar lo que Escobar llama el "lugar”, ya que éste condensa la relación entre el territorio, la biodiversidad, la cultura y las cosmovisiones, cuestión que establece la territorialidad específica; es decir, la manifestación de una influencia, alteración o control de los objetos, las personas y las relaciones en un territorio dado (Escobar 2011).

En este caso particular, muy claramente la construcción de un conjunto de represas para producir energía en la Patagonia define la apropiación privada de un bien público y la transferencia del mismo hacia otras regiones y territorios, pero dejando pasivos y resentimientos en el plano local. Esto significa, siguiendo a Martínez-Alier acumulación por desposesión y acumulación por costos ambientales (MartínezAlier 2011).

La Patagonia es importante porque ha constituido una frontera en sí misma, tanto física como cultural. Por sus dificultades de accesibilidad, es prácticamente desconocida para gran parte de la población, no hay vías longitudinales que conecten todo el territorio nacional y nos lleven hacia ella. Para acceder a esta zona por vía terrestre, las rutas argentinas son obligadas. Cuestión diametralmente opuesta a la amplia información que ha circulado en los últimos años sobre la riqueza que guarda y los intereses económicos asociados al territorio, como la existencia de las más importantes reservas de agua dulce, minerales, madera y energía para generar hidroelectricidad. Es un lugar de interés para el análisis social y territorial, en el que convergen distintas narrativas y de una tierra que ha tenido en algunos lugares colonizaciones que han logrado sobrevivir, como es obvio en las ciudades, pero el territorio en su conjunto no ha logrado ser conquistado a cabalidad, ya que no ha desarrollado una conectividad terrestre que una las distintas regiones. En ella existen tres grandes conflictos relacionados con realización de obras para la generación de energía: Central Hidroeléctrica Río Cuervo, Mina Invierno y Proyecto Hidroaysén (INDH 2012). Todos los proyectos son considerados de alto impacto medioambiental.

\section{Resistencia, Estado y capitalismo}

Las dos primeras décadas del siglo XXI bien podrían ser caracterizadas por el aumento de los conflictos ambientales, sino es el principal, con 
seguridad ocupa un lugar destacado cuando se analiza la acción colectiva en América Latina. En el caso de Chile, de norte a sur se configura un mapa de éstos conflictos; el estudio de la Consultora SIAE analizó los 100 proyectos que han enfrentado mayor oposición socioambiental en el país en los últimos doce años ${ }^{3}$, y señala que las inversiones hidroeléctricas ocupan el segundo nivel de conflictividad (22\%), en primer lugar se sitúan los conflictos mineros (29\%). En ellos se identifican principalmente tres actores que interactúan en los territorios y que generan dinámicas diferentes: comunidad, empresas y Estado (Bebbington 2007). El movimiento Patagonia Sin Represas se inscribe en estos resultados y representa el principal opositor a las construcciones de ese tipo.

La protesta social surge desde las localidades en defensa del territorio como espacio de vida y como recurso que le provee la base material para su desarrollo. La Cumbre de los Pueblos realizada en Santiago de Chile el 25, 26 y 27 de enero de 2013, refleja y sintetiza la actitud que adoptan las comunidades: "Frente al extractivismo... Extra-activismo". El movimiento Patagonia Sin Represas se enmarca en ese escenario y da cuenta de las reacciones y relaciones que los habitantes de la región Aysén, han ido construyendo en defensa de su territorio desde que fue anunciado el proyecto Hidroaysén.

\section{Patagonia sin Represas: contra la colonización material y simbólica de la naturaleza}

Una amplia bibliografía en los últimos años en torno a estos conflictos, ha observado una secuencia de etapas que tiende a ser común en su desarrollo ${ }^{4}$, es decir, en las formas de organización y acciones que las comunidades van generando en el proceso de resistencia frente al capital global y a la colaboración del Estado. El análisis de Patagonia Sin Represas permite observar la conflictividad social contemporánea, entendiendo que los movimientos sociales son síntomas y expresiones de ésta, revelando las estructuras sociales, las instituciones y las prácticas a las cuales los sujetos de la acción colectiva se oponen, configurando un campo de disputa por la apropiación de recursos materiales y simbólicos a los cuales se les atribuyen valores diferenciados (Castells 2006; Melucci 1999).

\section{El conocimiento del proyecto: Endesa va por la Patagonia}

La alerta se encendió tempranamente en el 2006. Un titular del día 22 de enero, del desaparecido Diario La Nación, anunciaba: “La pugna por un ‘proyecto país' de cuatro mil millones de dólares. Endesa va por la Patagonia”, y situaba a Aysén como el epicentro de una nueva “guerra verde”. El reportaje identifica como protagonistas, por una parte a Duglas Tompkins, Enrique Alcalde y Víctor Hugo Pucci; y por otra, a Endesa, la Sociedad de 
Fomento Fabril y el Gobierno. Fuerzas desiguales: un ecologista y dos empresarios de la región que se oponen frente al capital trasnacional y al Estado. Sin embargo, son los habitantes de la comuna de Cochrane de 2800 habitantes, los principales “contribuyentes al progreso nacional” (Barabás y Bartolomé 1992:8), quienes se reconocen como mayormente afectados por el proyecto y los que manifiestan su preocupación cuando se empiezan a conocer y a discutir algunos detalles sobre la inundación que provocaría la mega obra.

Así lo manifestó ese mismo año el presidente y fundador de la Agrupación Defensores del Espíritu de la Patagonia5: "Estamos preocupados por el impacto en la vida social, cultural y económica de los patagones y antiguos colonos de la décimo primera región. Es una zona tranquila, donde no hay delincuencia, alcoholismo ni drogadicción. En Cochrane vivimos 2800 personas y Endesa pretende traer 4000 trabajadores, que tienen otras culturas y costumbres. Con sólo 50 de ellos, hace unos días se registraron desórdenes en una discoteca"6. La mayoría de los habitantes de la región destacan, desde que se anunció la obra, como la principal dimensión afectada la cultural en tanto opera como una amenaza a la pérdida de costumbres de la región patagónica, dimensión que junto a otras se ha ido reafirmando como aspecto constitutivo de la identidad colectiva ${ }^{7}$. En retrospectiva, es importante observar aquí, cómo la preocupación inicial de los habitantes de la ciudad, en relación al impacto de la llegada de trabajadores, fue precisamente uno de los argumentos esgrimidos por el Comité de Ministros del Presidente Piñera (2014), apelando a la falta de estudios al respecto, que fundamentó postergar la aprobación del proyecto, trasfiriendo esta decisión para el próximo gobierno.

En esa dirección apuntaban igualmente las declaraciones de la ciudadana aysenina Ana Velásquez, en una columna en el periódico El Divisadero, de Coyhaique (15/11/2006), titulada "Las represas y el sentir patagón”, en la que se refería en los siguientes términos a la población local: "acá la gente es serena y paciente, simple y sencilla, contemplativa y silenciosa, amable y sincera; también desconfiada, pero por sobre todo es respetuosa y agradecida con la naturaleza y los parajes con que nos bendijo Dios”. Al mismo tiempo, reflexiona: “Es difícil para nosotros poder dimensionar cómo funciona el mundo globalizado y capitalista. Me refiero al hecho de que es bien sabido que en la actualidad la vida de las personas de estas regiones australes se decide en conversaciones de cualquier cafetería de países de Europa o Norteamérica y que nuestro futuro pueda estar en manos de 4 ó 5 personas que tienen tanto dinero y quieren seguir aumentando su capital con los recursos naturales que en forma privilegiada están en la zona austral de Chile”. De esta forma, desde el inicio del conflicto se coloca en cuestión la autonomía de los actores regionales en torno al uso y apropiación de su territorio, especialmente pensado desde la realidad local y considerando el espacio/ tiempo entre los pocos que deciden lejos sobre los muchos que residen en la región y temen por su futuro. 


\section{Interiorización de los detalles del proyecto y la presión que ejerce la empresa}

La percepción de vulnerabilidad de los derechos sociales, culturales y políticos, y el sentimiento de las posibles pérdidas afectivas, emocionales, psicológicas, materiales y culturales se vuelvan más intensas en la medida que se inicia una campaña de difusión de informes técnicos y análisis por parte de distintos colectivos sociales locales, utilizando ampliamente las redes sociales como principal recurso para posicionar el conflicto en gestación.

Esta reacción se intensifica especialmente cuando ENDESA, inicia los estudios de prospección en diferentes comunas: camionetas de empresas contratistas de Endesa recorren el valle del Baker realizando estudios topográficos y de sondaje e instalan campamentos de color rojo, donde se emplazaría la central Baker. Las denuncias frente estas acciones ilegales de la empresa no se hacen esperar. Se formulan las primeras críticas respecto a las formas de inserción en la zona, la falta de entrega información clara respecto a las intervenciones en los diversos predios sin las autorizaciones jurídicas correspondientes.

A juicio de Alejandro Pucci, economista y miembro de la Agrupación Defensores del Espíritu de la Patagonia, la información que ha entregado Endesa ha sido muy vaga. Y en referencia a los habitantes del lugar señala: "Los colonos tienen poco nivel educacional, son muy permeables por la empresa asesora de la multinacional [Tironi y Asociados] ${ }^{8}$. La gente de Endesa ha prometido caballos a los propietarios de los ríos Ñadis y Neff, para entrar a realizar mediciones en los campos. Hay elementos de presión. Cuando se presentan frente a los colonos, les dicen que es un proyecto del Gobierno. Dos propietarios interpusieron recursos de amparo contra la empresa”.

\section{Del cuestionamiento a la franca oposición}

Las denuncias frente estas acciones ilegales de la empresa no se hacen esperar. El Director de la ONG ECOSISTEMAS, Juan Pablo Orrego, señalaba "El conflicto está muy polarizado. En un comienzo las organizaciones ciudadanas y ambientalistas optaron por informarse y estudiar el proyecto de ENDESA, pero a medida que la empresa, en forma bastante confusa, fue entregando información más concreta, hemos pasado del cuestionamiento a la franca oposición" ${ }^{19}$. Desde ahí en adelante, se puede decir que los ayseninos inician un proceso de empoderamiento de su territorio, el que en su geografía cotidiana e imaginaria han vivido casi insularmente. A través de la valorización de los recursos naturales, su historia en la lejanía, la desconfianza hacia el Estado, y como poseedores de una cultura "patagónica" que se ve amenazada en su continuidad, como también el futuro que desean, se refuerzan los elementos identificatorios y 
diferenciadores respecto del resto del país. Se narran a sí mismos a través de sus prácticas rurales y dan sentido totalizador a la propia experiencia, a la autoafirmación frente al centralismo de la capital, el mercado y la comunidad nacional.

Para la elaboración de su propio relato y realzar los atributos del territorio, comienzan a hacer circular por las redes sociales comentarios e informes científicos sobre los impactos de la construcción de represas en el mundo, como el Informe de la Comisión Mundial de Represas (ONU, 2000). Éste, a propósito de experiencias mundiales de los también conocidos Proyectos de Gran Escala (PGE) que pueden ser considerados una forma de producción ligada a la expansión de los sistemas económicos (Lins Ribeiro, 1985), indica entre los numerosos impactos socioculturales que producen las grandes construcciones los siguientes: a) Desintegración de comunidades y aumento de problemas mentales y físicos, b) Inadecuados programas de mitigación, reasentamiento y desarrollo para desplazados, c) Permanente desconsideración de comunidades ubicadas aguas abajo de las represas, lo que ha conducido al empobrecimiento y sufrimiento de millones, d) Entre los grupos más pobres y vulnerables, las generaciones futuras deberán soportar costos sociales y ambientales sin obtener proporcionalmente beneficios económicos, e) Que el sector que sería inundado comprende 70\% de los suelos productivos de la provincia, y f) Que se espera la llegada de más de 4.000 trabajadores, principalmente hombres, lo que generaría impactos sociales importantes ${ }^{10}$. Además, una acción de impacto a nivel nacional e internacional fue la campaña visual de gigantografías que muestran los paisajes a ser intervenidos y los impactos sobre ellos, con tendidos eléctricos cruzando extensos territorios, flora y fauna amenazada de extinción y frases como “destrucción no es solución”.

\section{Las organizaciones inician acciones concertadas}

En esta etapa del proceso, la comunidad promueve diferentes iniciativas tendientes a informar y concientizar a la ciudadanía acerca del impacto en la región que el proyecto generaría. Por ejemplo, con ocasión del día mundial del medio ambiente (5/06/2007), en Coyhaique se realizó una manifestación que según Miriam Chible, presidenta de la Corporación Privada para el Desarrollo de Aysén, "Es una actividad simbólica mediante la cual quisimos representar a la gente, a la comunidad que pasa por el Paseo Horn qué significa tener el paso cerrado por una represa, mostrando que se corta el camino a la vida, al diario vivir, a todo. Y esa sensación quisimos crear hoy, aunque la gente se sintió un poco sorprendida le llamó mucho la atención y puede servir para reflexionar”11.

Una segunda acción que interesa destacar en ese momento del proceso es de carácter binacional, lo que demuestra que, tanto desde el lado chileno como argentino de la Patagonia, la población y organizaciones comenzaban a construir una conciencia de unidad, de problemática común y de reconocimiento "territorial” que va más allá de las fronteras nacionales. 
En junio del 2007, se efectuó el encuentro binacional “Agua Pura=Agua Dulce”, en Los Antiguos, tendiente a generar acciones desde la sociedad civil chilena y argentina. En el Encuentro el conflicto es definido como "el saqueo de la Patagonia por los intereses de empresas trasnacionales de la minería y la electricidad”. Las dos jornadas contaron con unas 150 personas, dirigentes y autoridades de las localidades patagónicas argentinas de: Los Antiguos, Perito Moreno, Rada Tilly, Caleta Olivia, Sarmiento, Pico Truncado, Puerto Deseado y Las Heras, y chilenas de Chile Chico, Caleta Tortel y Coyhaique. En este caso, se trata de la defensa del territorio como un espacio común donde transitan argentinos y chilenos, y las fronteras se tornan inexistentes. Como acuerdo, una de las acciones principales refiere a demandar a los Estados chileno y argentino en la regulación y cumplimiento de la normativa vigente, especialmente el Tratado de Medioambiente con el Protocolo de Recursos Hídricos Compartidos suscrito por ambas naciones en 1991. Este Encuentro se considera un hito en las primeras acciones tendientes a la internacionalización del conflicto, y además en la apelación directa que se formula a los Estados a garantizar los derechos establecidos en acuerdos internacionales.

En 2007, ciudadanos y un grupo de organizaciones ambientales, sociales y productivas, se organiza en torno al Consejo de Defensa de la Patagonia (CDP), reuniendo a más de 70 organizaciones nacionales e internacionales que aportan desde sus competencias a esta emblemática cruzada, compartiendo una visión común sobre la vocación de este territorio austral, ligada al desarrollo de actividades productivas tradicionales en baja intensidad, y fundamentalmente a la conservación, el turismo y un desarrollo genuinamente sustentable, concordante con la identidad auto asumida por la Región de Aysén como "Reserva de Vida"12.

Se observa como una red doméstica, se integra a organizaciones nacionales e internacionales de más 23 países. En este caso, por ejemplo, se encuentran: Associazione Studi America Latina organizaciones de España, Italia, Estados Unidos, Argentina, Bolivia, Canadá; y a nivel nacional Greenpeace Chile, Fundación Terram, Ecosistemas, CODEFF. Casi todas difunden campañas internacionales (vía web) que posibilitan la interacción a nivel mundial, con problemáticas e intereses comunes, algunas con orientación hacia recursos hídricos, bosques, cuencas entre otros, promoviendo la creación de una red de organizaciones y movimientos sociales de carácter transnacional como medida de resistencia a la intervención de la economía global en el territorio local. Este Consejo agrupa un conjunto heterogéneo de actores sociales: organizaciones sociales, empresarios de la región, ambientalistas, ecologistas, políticos, dirigentes sociales y organizaciones no gubernamentales nacionales e internacionales, cada una con intereses particulares, sin embargo organizados en torno a una identidad colectiva: “ser patagón” y la defensa de un territorio ambientalmente sustentable. 


\section{La defensa territorial basada en la Identidad local y en el valor mundial como reserva de vida}

Lo señalado permite visualizar un período inicial del conflicto, germen de la emergencia de la campaña PATAGONIA SIN REPRESAS, marca registrada de la acción colectiva local, nacional e internacional contra el proyecto Hidroaysén. De acuerdo al Consejo de Defensa de la Patagonia, "Esta campaña espera alertar las conciencias y corazones de todos los chilenos y ciudadanos del mundo, acerca del peligro que se cierne sobre la Patagonia Chilena y sus maravillosos ríos. En particular se hace un llamado a las autoridades nacionales y regionales para que mediten muy bien sus decisiones y no sucumban ante la presión de los mismos monopolios eléctricos y sectores industriales que nos llevaron a esta situación de crisis energética por su miopía mercantil, que sólo les permite percibir el lucro privado y es ciega al bien común de la nación ${ }^{13}$.

La Cabalgata Patagonia sin Represas, realizada por un conjunto de agrupaciones y ciudadanos durante nueve días por la región, concluyó con la Declaración de Aysén (27 de noviembre de 2007). En este documento ya se identifican claramente las reivindicaciones ciudadanas, en su mayoría orientadas al Estado chileno. La Declaración refiere al agua como bien público y un derecho humano; a la necesidad de contar con un programa de gestión integrada de manejo de cuencas; Una política energética sustentable y la coherencia entre una política de desarrollo y los instrumentos de planificación y fomento productivo. Al Estado se demanda su rol de garante del bien común y a su institucionalidad ambiental mejorar la calidad técnica en el sistema de evaluación del impacto ambiental.

La oposición y resistencia de los diferentes actores sociales, se fundamenta en referencias materiales y en representaciones del territorio que definen como santuario de la naturaleza, patrimonio de la humanidad, fuente de vida, reserva de vida, y en algunos casos definido como "regalo de dios". El Obispo de la región, Monseñor Luis Infanti de la Mora, cuyas opiniones han sido catalogadas como las de un "intransigente ambiental", en carta pastoral, señala: "Dañar la naturaleza en Aysén es ofender a los ayseninos y a toda la humanidad, así como por el contrario, amarla es amar a ambos".

El principal argumento del Obispo en relación a la defensa del territorio patagónico, se ha construido en torno a la oposición: naturaleza-capital, la destrucción de la primera, como consecuencia la inversión de empresas privadas, mediante "la construcción de megacentrales hidroeléctricas, reconociendo los riesgos y el impacto negativo tanto en la dimensión ecológica como en la socio-cultural. Científicos, políticos y empresarios tienen oficialmente legitimada su palabra sobre estos proyectos. Pero sería un grave insulto, y un escandaloso error de la democracia, no considerar seriamente a los que tenemos la ciencia, el amor y el arte de vivir en estas tierras. (Carta de Obispo Infanti $)^{14}$ 
Los actores locales principalmente defienden el derecho a decidir sobre el modelo de desarrollo en el territorio, en la página http:// www.patagoniasinrepresas.cl, específicamente cuando se define el problema y la amenaza que genera la construcción de las represas, se indica como factor irreversible, de la misma manera que lo hacen Nature y New York Times: "La transformación irreversible de un vasto territorio de alta pristinidad en un lugar lleno de represas y cruzado por enormes tendidos eléctricos. Si estos proyectos fuesen autorizados, en la práctica se estaría permitiendo que el monopolio eléctrico que persigue su implementación por intereses comerciales privados, se apropie gratuitamente de este valioso capital natural de todos los chilenos, y que sepulte, de paso, el sueño de Aysén de ser una región capaz de conservar su calidad ambiental. Reconocen que en todas las estrategias de desarrollo regional de Aysén y en otros lineamientos públicos relacionados, prevalece con fuerza la idea del producto turístico de alta calidad. En función de ello se han incorporado importantes territorios al Sistema Nacional de Áreas Silvestres Protegidas del Estado y se han realizado numerosas inversiones privadas en proyectos de pesca recreativa, montañismo, cabañas, hotelería, entre otros, y actualmente se encuentran muchos proyectos de este tipo en estudio y desarrollo, producto de los positivos resultados económicos obtenidos en este rubro ${ }^{15}$.

\section{Establecimiento de redes: los aliados influyentes y la internacionalización del conflicto}

Dos ejemplos grafican el establecimiento de redes con organizaciones internacionales y las acciones que se promueve lejos de las fronteras locales donde se sitúa el conflicto. En España e Italia, se realizaron campañas en contra de la construcción de las represas. No es solo la construcción de represas, sino que se desarrollaría con el cableado el sendero talado más largo del mundo. En mayo de 2008, Greenpeace España lanzó una “ciberacción” en defensa de la Patagonia Chilena. Tanto en Chile como en España, Greenpeace movilizará a sus “cyberactivistas”, centrando su protesta contra ENDESA, Juan López de Uralde, director de Greenpeace España, declaró al respecto: "se llena la boca con campañas de publicidad pseudoecológicas, mientras pretende destruir el medio ambiente con su actividad $^{16}$.

Con el nombre "Campagna Patagonia Senza Dighe", dos años más tarde (21/09/2010) fue lanzada oficialmente la Campaña Patagonia Sin Represas en la ciudad de Roma. En la época Caterina Amicucci de la Campagna per la Riforma della Banca Mondiale señalaba lo siguiente: "No podemos ignorar la información que nos ha llegado de las organizaciones chilenas, no sólo porque la involucrada es una empresa italiana, ENEL, con más del $30 \%$ de propiedad estatal, sino también porque el caso de las represas en Patagonia es paradigmático de un modelo de desarrollo equivocado y perjudicial"17. 
A finales de 2010, el Coordinador Internacional del Consejo de Defensa de la Patagonia, señalaba lo siguiente: "Es increíble, retrógrado y sospechoso que en Chile, en el siglo XXI, se sigan planteando proyectos como Hidroaysén, y el uso masivo de carbón. Esto solo se explica por la carencia de una política energética nacional y un desarrollo energético entregado al implacable mercado e impulsado exclusivamente por la lógica del negocio privado. Es imperativo transitar a una lógica orientada por el bien común y la sustentabilidad ambiental. Se trata de un cambio de paradigma insoslayable" ${ }^{\prime 18}$.

\section{Acciones que impiden la aprobación del proyecto y fortalecen la defensa del territorio}

En el trascurso de casi diez años, el repertorio de acciones se ha diversificado e intensificado en la región, el país y a nivel internacional, posicionando el conflicto en diferentes escalas interconectadas, principalmente a través del uso de redes sociales y todos los recursos tecnológicos que han permitido unir la acción colectiva local con la global. Demostrando así, que proyectos como Hidroaysén forman parte de una lógica económica privatizadora y expropiadora, directa o indirectamente promovida por los Estados en el marco del proceso de globalización del capitalismo extractivista. Todos los actores que se oponen al proyecto de la construcción de las represas y de las líneas de transmisión, a lo largo del conflicto ha mostrado una diversidad de iniciativas que van desde las más tradicionales como manifestaciones/marchas callejeras, vigilias en torno de los edificios que albergan servicios públicos regionales y locales, actividades artísticas, mateadas, fiestas costumbristas, además de recursos gráficos y audiovisuales de divulgación y concientización, acciones que se orientan a mantener activa la movilización en defensa de la Patagonia chilena, y a reforzar el "espíritu y la identidad patagónica”, y aquí cabe destacar las acciones realizadas mediante el uso de los recursos judiciales que le permiten a la ciudanía defender su territorio.

\section{La judicialización del conflicto Hidroaysén}

Una de las estrategias utilizadas por el movimiento social, y todo indica que tiende a adoptarse como recurso permanente por las organizaciones que se oponen a la construcción de represas u otros proyectos de infraestructura, es la defensa a través de la Institucional ambiental, y toda la legislación vigente que protege los derechos de los ciudadanos, y en el caso de los conflictos ambientales, el principal derecho que se reivindica/ demanda al Estado, es el derecho a la vida, el cual en todas sus dimensiones se ve amenazado por la construcción de proyectos de este tipo o aquellos generados por la extracción minera, sector forestal, la agroindustria, entre otros. En ese sentido, los defensores de la Patagonia sin Represas enmarcan sus acciones en el sistema judicial, político, y administrativo del país. 
El uso de los recursos legales también se extiende al extranjero, como parte de las estrategias desarrolladas en la internacionalización del conflicto, valiéndose de aliados influyentes. La denuncia por violación al Acuerdo de Cooperación Ambiental presentada y acogida a "La Comisión para la Cooperación Ambiental de Canadá (CCAC), acogió una segunda denuncia en contra de la construcción del proyecto Hidroaysén, presentada por el Consejo de Defensa de la Patagonia y ordenó al Estado chileno que entregue una "respuesta" para explicar el incumplimiento al Tratado de Medio Ambiente firmado entre Chile y Argentina, vigente desde 1991 y la infracción a la ley nacional sobre la materia ${ }^{19}$ (http://www.olca.cl/oca/chile/ region11/represas57.htm). El abogado del Consejo de Defensa de la Patagonia, Marcelo Castillo, afirmó que con esta resolución el país del norte "lleva a Chile ante el banquillo de los acusados" y que la buena fe y el respeto ante la comunidad internacional del Estado y del gobierno del presidente Piñera “está en juego” por el incumplimiento de la legislación ambiental.

Como se observa, una parte significativa de la campaña en defensa de la Patagonia ha tenido como escenario los tribunales de justicia, donde la ciudadanía ha utilizado todos los recursos que la legislación le permite para ejercer un rol fiscalizador. A pesar de las limitadas atribuciones que la legislación ambiental permite en materia de participación ciudadana, los ayseninos han dejado de manifiesto un conjunto de irregularidades en el proceso de evaluación y aprobación del proyecto. Por ejemplo: Informes Técnicos, anuncio de aprobación en página de inversionistas antes de la aprobación, modificación de legislación ambiental que reduce plazos y exigencias, entre muchos otras.

En febrero de 2011, y haciendo uso de la Ley de Transparencia, seis agrupaciones de la Región de Aysén la Agrupación de Defensores del Espíritu de la Patagonia de Cochrane, la Agrupación Defensores de la Cuenca del Murta, la Agrupación Herederos de la Patagonia de Villa Cerro Castillo, el Comité pro Defensa de la Flora y Fauna, la Corporación Privada para el Desarrollo de Aysén (CODESA) y el Colectivo Autónomo por la Patagonia (CAPP) solicitaron a 26 servicios públicos los documentos que sustentaron la elaboración de sus pronunciamientos de noviembre de 2010 sobre el Estudio de Impacto Ambiental (EIA) de Hidroaysén, y una parte importante de ellos ha señalado que no hay correos electrónicos, citaciones a reuniones de trabajo, pre-informes técnicos ni comunicación interna alguna relacionada con el proceso de evaluación. Las organizaciones con ese tipo de medidas buscan conocer cómo se desarrolló el trabajo en los órganos del Estado y constatar si hubo presiones de algún tipo para dirigir la evaluación técnica. Ante las nulas y esquivas respuestas, ingresan reclamaciones ante el Consejo para la Transparencia.

Asimismo, las organizaciones sociales posterior a la aprobación del proyecto (mayo de 2011), como una acción tendiente a paralizar la construcción de las represas, solicitaron a la Municipalidad de Coyhaique, mediante la entrega de 1782 firmas, la realización de un plebiscito sobre dos temas: 
Modificación del uso de suelo que prohíba la infraestructura energética y que se establezca la incompatibilidad de las torres de alta tensión con el desarrollo turístico y de conservación con la comuna (21 de agosto 2011) ${ }^{20}$.

Como corolario de lo anterior, las decisiones adoptadas por las diferentes instancias que componen la estructura ambiental, cada vez se encuentran más desacreditadas en sus funciones, especialmente señalan que su implementación no favorece a las comunidades ni a la protección de recursos naturales del país. Se cuestiona en forma permanente la composición de los comités técnicos, a las autoridades políticas regionales, y los Ministros que componen el Comitée ${ }^{1}$, instancia máxima que resuelve la aprobación de los proyectos. Durante el gobierno de Sebastián Piñera, los integrantes de este organismo, en su mayoría, presentaban conflictos de interés, dada su proveniencia del sector privado y las relaciones que mantienen con los grupos económicos que controlan la economía del país. Además, se cuestiona la operativa del Sistema de Evaluación de Impacto Ambiental, donde es el propio proponente quien contrata, directamente, a los centros de estudios que elaboran tanto la línea base como los estudios de impacto ambiental de sus iniciativas. Incluso llegan, mediante términos de referencia, a definir qué se estudia y qué no, y qué se pone en el documento que se presenta a evaluación, y qué no”22.

En la evaluación del coordinador de la Coalición Ciudadana por Aysén Reserva de Vida (CCARV) Peter Hartmann, uno de los logros de la Campaña Patagonia Sin Represas, fue "la sentencia dividida de la Corte Suprema (3 contra 2, con un voto de mayoría de un juez con acciones en Endesa) rechazando los recursos de protección interpuestos contra la aprobación de Hidroaysén en mayo de 2011”. No obstante, los resultados de este tipo de acciones también registran respuestas negativas. Es el caso del avance en el Congreso de las “Leyes Hidroaysén” (de Carretera Eléctrica Pública y de Fast Track para las Concesiones Eléctricas) que "beneficia el negocio eléctrico por sobre las demandas de una ciudadanía que aspira a una matriz energética verdaderamente limpia, segura y que respete la cultura, los ecosistemas y las vocaciones territoriales”.

La resolución de este concejo compuesto por 12 personas de confianza del Presidente de la República, es decir, alineado verticalmente y que determina la construcción del Proyecto Hidroaysén, implica un cuestionamiento diverso: 1) constituye un procedimiento que inspira la desconfianza sobre su neutralidad; 2) un cierto autoritarismo al tratar a puertas cerradas las decisiones que tienen que ver con los grandes temas y con el modelo de desarrollo; 3) la percepción de una influencia, a veces descarada, de lobbystas de las grandes compañías en la aprobación proyectos de inversión con alto impacto ambiental; y, 4) que son "poco deliberativos y transparentes” (Solimano 2012: 28), lo que constituiría una debilidad del sistema democrático por la ausencia de participación ciudadana.

Hasta marzo de 2014 se constata que la acción de Patagonia Sin Represas, ha logrado resultados de gran impacto en términos políticos, 
reafirmando así el mecanismo de la participación social como eje fundamental en la toma de decisiones a nivel local y regional, y al mismo tiempo desde una perspectiva global. De esta forma, el movimiento incorpora la doble dimensión: local/global, mostrando las indisolubles relaciones de conflicto que se generan en el espacio/tiempo, representando así otras formas de sociabilidad política, al margen pero también estableciendo vínculos con el sistema político institucional, prácticas que emergen y se observan en la sociedad contemporánea. Patagonia Sin Represas representa u objetiva un conflicto sociopolítico, con énfasis en lo ambiental, que acontece en un territorio concreto, donde el bien en disputa por diferentes actores es precisamente éste espacio, y el principal argumento en su defensa se estructura en su doble dimensión material y simbólica a través de la dimensión sociocultural y natural.

\section{El Estado: en nombre del bien público prevalece lo privado}

El Estado chileno, como muchos de los latinoamericanos, han configurado sus estrategias de crecimiento económico y, como motor del desarrollo, en una que es doblemente vinculante: exportaciones e inversiones. Por una parte, las exportaciones son de commodities, es decir, materias primas que genéricamente implican una gran remoción de bienes naturales que son movilizados sin valores agregados hacia otras zonas. Esta condición genera la figura de economías de enclave, fragmentando la imagen país. Por otra, las inversiones se concentran en cuestiones como agua, tierra y energía, lo que implica fuertes presiones ambientales y sociales.

Lo importante de esta doble estrategia son los efectos territoriales. Se constata una aguda fragmentación que da cuenta de lugares fuertemente ligados a la globalización como la minería, la agroindustria, la empresa forestal, de la celulosa y de los recursos del mar, y otras deprimidas y desatendidas por el Estado. Frente a esta condición expansiva del capital local y mundial, el territorio se entrega a éste, pero a la vez "se trata” de regularlo mediante estudios de impacto ambiental”, como una formalidad simplificadora acorde a las legislaciones vigentes.

En el caso de la Patagonia, y conforme a lo que se ha indicado más arriba, la baja densidad poblacional y pobre desempeño del Estado en términos de agenciamiento, instala por parte del capital la figura del territorio pasivo, baldío y un discurso respecto de que Aysén, lugar de emplazamiento del conjunto de las represas, "no puede seguir siendo una reserva de recursos”. Es decir, la lógica del capital observa aguas y tierras sin uso, y bosques no explotados. De ello se desprende una oposición básica: la potencialidad superlativa en términos económicos de este Chile interior y un desconocimiento de los usos que generaciones de colonos han desarrollado al alero de unas condiciones ambientales extremas, las que son anteriores inclusive a las divisiones políticas administrativas. Esto significa la reafirmación de una opción de desarrollo exclusivamente ligado al neo extractivismo y la propuesta de ejecución de megaproyectos, a la gobernanza 
mundial, a la aceptación acrítica de la posición subordinada de la economía nacional/regional, y la negación de opciones de otras formas de vida y de construcción de identidades ligadas a otros usos de los activos naturales o de economías y desarrollos locales no extractivistas.

La caja de resonancia de esta mirada territorial extractivista del capital, a la que se suma el Estado, está dada por los altos precios de materias primas como el cobre y la demanda asiática, ya que la recaudación producto de las exportaciones pondría a disposición recursos fiscales en las zonas no favorecidas por los procesos de la economía global. De este modo, el problema de la mega intervención en la Patagonia decodifica la globalización en el plano local, ya que expresa la verticalidad del modelo, la competencia entre territorios y la articulación entre éstos.

El problema de las opciones se centra en la negociación entre los actores: Estado, capital, acción ciudadana. Tratándose de energía, que es donde se ha puesto uno de los acentos para la Patagonia, sin duda hasta ahora el más importante a través del Proyecto Hidroaysén, el gobierno se ve interpelado por la empresa para que el Estado se comprometa con una agenda de largo plazo en materia energética y para que reafirme su compromiso pro-mercado y emprendimiento, asegurando las inversiones en energía que demanda la gran minería del cobre. Paralelamente, el segundo eje de problematización se encuentra asociado a la relación Estado y ciudadanía, en la medida que se instala como una condición generalizada la molestia ciudadana y la protesta masiva.

Por ello, tres gobiernos se han sucedido desde que se anunció el proyecto, sin que las decisiones u objeciones se hayan resuelto sin tensiones o recriminaciones. Así, desde los aparatos del Estado se ponen en marcha los dispositivos favorables al proyecto. El ex--ministro de Energía Jorge Rodríguez Grossi, al ser consultado sobre la oposición a los estudios que realizaba ENDESA, iguala a los ciudadanos, agrupaciones, corporaciones, ONGs y fundaciones a la transnacional, y su respuesta es categórica: "Probablemente, van a tener más dinero para hacer más oposición. Pero aquí no hay nadie que tenga más derecho que otro ciudadano. Esta inversión sale en todas partes porque hay un millonario norteamericano que está ahí con sus tierras y otro señor que es multimillonario y dueño de la salmonera más grande de Chile, que contamina en la misma región. El bien público manda por sobre el interés privado. Es inaceptable que traten de impedir los estudios previos de Endesa. Es antipatriótico”. ${ }^{23}$

\section{Conclusiones}

El proyecto Hidroaysén revela seis elementos que le son consubstantivos a todos los grandes emprendimientos extractivos del país: 1) refuerza el modelo de desarrollo sustentado en la extracción de recursos naturales, 2) permite la expansión del sistema económico y constituye por su envergadura un acontecimiento a nivel mundial, 3) afianza el proceso de 
mercantilización de los bienes comunes naturales, sin que éstos puedan siquiera puedan ser considerados bienes públicos, 4) indica un déficit de participación ciudadana, especialmente en los proyectos que afectan la territorialidad y la vida de las comunidades, 5) mantiene como norma y pasivo la fragilización de los ecosistemas y la aparición de importantes pasivos ambientales, 6) acentúa la desconfianza hacia la empresa privada, la institucionalidad del Estado y sus representantes.

Estos elementos, hablan también de la heterogeneidad estructural del país, de marginalidad, expropiación, dependencia, impactos ambientales y sociales, movimiento social, Estado, centralismo, institucionalidad, funcionarios de confianza, sector privado. En su conjunto, los encadenamientos y reacciones institucionales y ciudadanas definen situaciones y hechos que transcurren en el tiempo, los que están más allá de la planificación y ejecución del proyecto.

Estos actores y elementos configuradores del conflicto se concentran y densifican porque hay una cultura territorializada en el paisaje, prácticas locales institucionalizadas y pertenencia socio territorial. La toma de conciencia y autoafirmación las podemos encontrar con claridad en dos niveles en la oposición al Proyecto Hidroaysén: a) como ampliación y radicalización de la plataforma representativa y discursiva sobre el valor del paisaje y modo de vida local y regional, y b) en la expresión ciudadana de rechazo al centralismo, en los sentimientos de desprotección, indignación, y de tener una autoridad obsecuente frente al poder de las grandes compañías, como lo ha identificado en sus denuncias el movimiento Patagonia Sin Represas.

El conflicto en contra de Hidroaysén constata además un déficit de participación política y de construcción de ciudadanía, ya que el Estado refuerza la posición de actores dominantes en detrimento de aquellos que son más débiles y desprotegidos. En ello, sin duda, es la mayor movilidad de los capitales lo que provoca una condición de chantaje locacional y de reforzamiento de dispositivos -en términos de Foucault-, en la medida que las poblaciones desposeídas y mal atendidas por el Estado se ven muchas veces forzadas a ceder parte de su propia historia y relación con la naturaleza, aceptando riesgos socioambientales frente a ofertas de trabajo y mejoras en electrificación, vivienda, becas estudiantiles, ayuda en salud humana y animal, bajo el rótulo de “responsabilidad social empresarial”.

Claramente no existe la autonomía regional para la toma de decisiones sobre el propio territorio, lo que implica un cuestionamiento al modelo político y de elección de autoridades, así como problemas de ordenamiento territorial. Cuestiones de tal envergadura y sensibilidad debiesen ser tratadas esencialmente en el ámbito de público, con la participación ciudadana. No menos importante es la escasa transparencia, la ausencia de pluralismo, la poca visibilización de las responsabilidades en la toma de decisiones. Doce personas de confianza del Presidente de la República deben tomar la decisión sobre la más importante intervención territorial en el país, e iniciar 
una tala de bosques para construir el mayor sendero del mundo por donde pasen los cables de su tendido eléctrico.

El conflicto en torno al Proyecto Hidroaysén indica una necesidad de cambio en la relación sociedad civil y Estado. Aparece como sinónimo de déficit del modelo de gobernabilidad, y por lo mismo de falta de control en la esfera económica por parte de los gobiernos y la ciudadanía. Esto ha posibilitado que el movimiento social Patagonia Sin Represas configure un repertorio de acciones como las detalladas, que han permitido su visibilidad nacional e internacional, así como cuestionar la legitimidad emblemática de aquello que ocurre con el sistema democrático y económico en el país.

El movimiento constituye una lucha territorializada, que mediante nuevas prácticas de acción política y el uso de los recursos judiciales trasciende el espacio local, para reivindicar en el espacio global el derecho al medio ambiente de una región prístina y la posibilidad de crear parques de la tierra y para la tierra. La movilización social en contra de este proyecto ha sido creciente, no solo atañe en sus consecuencias a los habitantes de la Patagonia, el problema es nacional y de la humanidad, en la medida que Aysén se reconoce como "reserva de vida", "santuario de la naturaleza", "patrimonio de la humanidad”, “fuente de vida”, "reserva de vida”, y otras variadas representaciones de la Patagonia. Hoy, no son expresiones exclusivas de los aiseninos, ni de todos quienes defienden la región austral del país, el discurso local es reconocido globalmente, y es mediante la acción colectiva donde este se unifica, dotándolo de contenidos en las más diversas dimensiones del quehacer social.

Política y estratégicamente el movimiento social introduce las ideas de lo similar y lo equivalente como ocurrencia del modelo; reconfigura la solidaridad, la identidad y la conectividad social. También, su virtud está en explicitar las posiciones de los actores en conflicto, en convocar a una audiencia nacional e internacional, manifestar que el país quiere cambios, respeto por las formas de vida territorializadas y por la valorización de la biodiversidad.

\section{Consideración final}

Con fecha 10 de junio de 2014, el Comité de Ministros de la Presidenta Michelle Bachelet, encabezado por el titular del Medio Ambiente, Pablo Badenier, decidió rechazar de manera unánime el proyecto hidroeléctrico Hidroaysén. Existían 993 observaciones pendientes asociadas a variables como paisaje y turismo, medio humano, procedimientos legales, medio físico e hidrología, ecosistema terrestre y ecosistema acuático, que constituían reclamaciones que no habían sido consideradas o habían sido insuficientemente ponderadas por los miembros de la Comisión de Evaluación de la Región de Aysén, de la administración del Presidente Sebastián Piñera. 
Polis, Revista Latinoamericana, Volumen 14, $N^{\circ}$ 40, 2015

\section{Notas}

${ }^{1}$ Este trabajo es parte del proyecto Fondecyt 1120795 “Etnografía de la colonización y recolonización de Chiloé Continental. Actores, intercambios y conflictos”.

${ }^{2}$ La Integración de Infraestructura Regional Sur Americana (IIRSA), corresponde a un acuerdo interestados, firmado por doce presidentes (2000), con el objetivo de establecer un plan de implementación de infraestructura dividida en 10 ejes, con aproximadamente 400 mega proyectos que incluyen carreteras, puertos, telecomunicaciones, represas y puentes, con un coste que se eleva a más de 37 mil millones de dólares (www.iirsa.org).

3 “SIAE trabajó en base a un universo que incluye a todos los conflictos socioambientales registrados en Chile desde el 2000 hasta la actualidad. La fecha de cierre para la recolección de datos fue el 9 de julio de 2012. El procesamiento de ellos finalizó el 31 de agosto. Los datos que se presentan en el estudio corresponden a información pública disponible en instituciones del Estado, investigaciones académicas y medios de comunicación tradicionales y digitales. Para establecer el ranking se utilizaron diversas variables. Entre ellas, las concernientes a los grupos opositores (nivel de articulación, cantidad de actores, involucramiento de ONGs), la cobertura comunicacional y la judicialización, entre otras.” (Qué Pasa, noviembre 2012).

${ }^{4}$ http://es.scribd.com/doc/94593138/Empresas-Extractivistas-en-los-Territorios-Juegode-Mascaras-que-hay-que-Descifrar. Seguiremos en este trabajo la secuencia de esas etapas, revelando las particularidades de este movimiento.

${ }^{5}$ Reúne en torno de 500 personas, especialmente campesinos y potenciales afectados por las inundaciones.

${ }^{6}$ Agencia de Noticias, IPS 19 de abril de 2006 www.ipsnoticias.net

${ }^{7}$ Melucci (1999) define tres dimensiones para el concepto de identidad colectiva: Formulación de estructuras cognoscitivas comunes relativas a los medios, fines y ámbitos de acción (valorar ambiente, definiciones, costos, disponibilidad de recursos (cognitivos e relacionales, lideres, militantes, activistas, en qué nivel de acción se implican diversos individuos... y la activación de las relaciones entre los actores (actúan, se comunican, negocian, deciden). Realización de inversiones emocionales que permiten a los individuos reconocerse.

${ }^{8}$ Una de las más importantes e influyentes empresas de lobby en el país.

${ }^{9}$ IPS, 19 de abril de 2006.

10

(http://www.patagoniasinrepresas.cl/final/ contenido.php?seccion=problema_impactorepresas).

${ }^{11}$ www.aisenreservadevida.cl

12 (http://www.ecosistemas.cl/web/campanas/patagonias-sin-represas.htm

13 http://www.patagoniasinrepresas.cl/final/contenido.php?seccion=nuestracausa. 
${ }^{14}$ http://www.radiosantamaria.cl/rsm/noticias/3021-monsenor-infanti-recibe-apoyo-decoordinador-de-coalicion-ciudadana-por-aysen-reserva-de-vida.html

15 (http://www.patagoniasinrepresas.cl/final/contenido.php?seccion=problema).

16 http://www.eldivisadero.cl/noticia-24302.

17 http://www.ecosistemas.cl/1776/article-90472.html.

${ }^{18}$ (http://www.eldivisadero.cl/noticias/?task=show\&id=24260).

${ }^{19}$ La solicitud de informes desde Canadá coincide con la visita que hizo a Chile Fulvio Conti, el máximo ejecutivo de ENEL, para reunirse con el Presidente Piñera controladora de Endesa-, puntualmente para que el Mandatario se "involucre" en el proyecto Hidroaysén (www.elmostrador.cl 11 de mayo de 2010).

20 http://radio.uchile.cl/noticias/119376/

${ }^{21}$ Integrado por el Ministro del Medio Ambiente, que lo preside, y los Ministros de Salud; de Economía, Fomento y Turismo; de Agricultura; de Energía y de Minería. Su función es conocer y resolver los recursos de reclamación que se presenten en contra de las resoluciones que rechacen o establezcan condiciones o exigencias a un Estudio de Impacto Ambiental; las reclamaciones en contra de las resoluciones que realicen la revisión de una Resolución de Calificación Ambiental, así como los recursos de reclamación presentados por las personas que hubieren formulado observaciones al Estudio de Impacto Ambiental y que estimaren que sus observaciones no han sido consideradas (Ley $\mathrm{N}^{\circ}$ 19.300).

${ }^{22}$ http://www.pysnnoticias.com/2011/02/03/investigacion-de-tesistas-del-mit-siembradudas-sobre-eia-de-hidroaysen/

${ }^{23}$ (http://www.olca.cl/oca/chile/region11/represas01.htm 
Polis, Revista Latinoamericana, Volumen 14, $N^{\circ}$ 40, 2015

\section{Bibliografía}

Acosta, A. (2009), La maldición de la abundancia, Ediciones Abya-Yala., Quito, Ecuador

Alimonda, H. (coord.). (2011), La Naturaleza colonizada. Ecología Política y minería en América Latina, CLACSO, Buenos Aires, Argentina.

Alimonda, H. (2011), "La coloniedad de la naturaleza. Una aproximación a la ecología política latinoamericana”. En La naturaleza colonizada. Ecología política y minería en América Latina. Alimonda, H. (Coordinador), CLACSOEdiciones CICCUS, Buenos Aires, Argentina, p. 21-58.

Barabás, A.; Bartolomé, M. (1992), “Antropología y relocalizaciones”. Alteridades. 2(4): p. 5-15, Disponible en: http://www.uam-antropologia.net/ pdfs/ceida/alt4-1-barabas.pdf

Barabás, A. (2004), “La construcción de los etnoterritorios en las culturas indígenas de Oaxaca”. Desacatos. 14; p. 145-168, Primavera-Verano. Disponible en: http://www.ciesas.edu.mx/desacatos/14\%20Indexado/ 2\%20Esquinas\%201.pdf

Bebbington, A. (Editor) (2007), Minería, movimientos sociales y respuestas campesinas. Una ecología política de transformaciones territoriales. Lima, Perú. IEP/Cepes.

Brandão, C. (2009), “Acumulação primitiva permanente e desenvolvimento capitalista no Brasil contemporâneo”. En SEIDL, Daniel (Coordenação editorial) Capitalismo globalizado e recursos territoriais, p 39-70, Lamparina editora, Rio de janeiro, Brasil..

Castells, M. (2006), El poder de la identidad. La era de la información: economía, sociedad y cultura (Vol. 2), Siglo XXI, México, DF

Delgado, G. (2013), “Presentación”. En Delgado, G (coord.). Ecología política del extractivismo en América Latina: casos de resistencia y justicia socio-ambiental p. 9-18, CLACSO, Buenos Aires, Argentina..

Escobar, A (2011), “Ecología Política de la globalidad y la diferencia”. En: Alimonda, H. (comp.) La Naturaleza colonizada. Ecología Política y minería en América Latina, p. 61-92, CLACSO, Buenos Aires, Argentina....

Estudio Nacional de Opinión Pública N63. Centro de Estudios Públicos. Noviembre-Diciembre 2010. [Fecha de consulta: 11 junio 2014]. Disponible en: http://www.cepchile.cl/bannerscep/bdatos_encuestas_cep/ base_datos.php

Gudynas, E. (2009), “Diez tesis urgentes sobre el nuevo extractivismo. Contextos y demandas bajo el progresismo latinoamericano actual”. En 
VV.AA. Extractivismo, política y sociedad, p. 187-225. CAAP(Centro Andino de Acción Popular) y CLAES (Centro Latinoamericano de Ecología Social). Quito, Ecuador. Serie Cuadernos de Capacitación..

Harvey, D. (2004), “El ‘nuevo’ Imperialismo: acumulación por desposesión”. En Panitch, L; Colin L (Editores). El Nuevo Desafío Imperial, p. 99-129, CLACSO Buenos Aires, Argentina.

Lamberti, M. (2011), “Una lucha a "cielo abierto”. El caso del Frente Amplio Opositor a Minera San Xavier”. En: Alimonda, H. (comp.) La Naturaleza colonizada. Ecología Política y minería en América Latina, p. 303-331. CLACSO, Buenos Aires, Argentina.

Larraín, S. (2014), “El lucro con las aguas chilenas”. Le Monde Diplomatique. Mayo 2013. [Fecha de consulta: 11 junio 2014]. Disponible en: http:// www.lemondediplomatique.cl/El-lucro-con-las-aguas-chilenas.html

Leff, E. (2006), “La ecología política en América Latina. Un campo en construcción”. En Alimonda, H. Los tormentos de la materia. Aportes para una ecología política Latinoamericana, p. 21-40, CLACSO. Buenos Aires, Argentina.

Lins Ribeiro, G. (1987), “¿Cuánto más grande mejor? Proyectos de gran escala: Una forma de producción vinculada a la expansión de sistemas económicos”. Desarrollo Económico, Vol. 27(27); p.3-28.

Lins Ribeiro, G. (1985), “Proyectos de gran escala: hacia un marco conceptual para el análisis de una forma de producción temporaria”. En Bartolomé, L. J. (comp). Relocalizados: Antropología social de las poblaciones desplazadas, p. 49-66, Ediciones del IDES, Buenos Aires, Argentina.

Martínez-Alier, J. (2011), “Macroeconomía ecológica, metabolismo social y justicia ambiental”. En Revista Historia Actual. Vol. 9 (№ 9): 148-168, Disponible en: http://historia-actual.org/Publicaciones/index.php/rha/article/ viewArticle/745

Martínez-Alier, J (2003), Environmentalism of the Poor. A study of ecological conflicts and valuation. UK. Edward Elgar Publishing.

Melucci, A. (1999), Acción colectiva, vida cotidiana y democracia, El Colegio de México, Centro de Estudios Sociológicos, México, DF

Observatorio Latinoamericano de Conflictos Ambientales (OLCA) de Chile.( 2003-2004), Estrategias de gestión de las diferentes etapas del conflicto Compañía Minera Los Pelambres vs. Pescadores de Los Vilos y Agricultores de los Valles del Choapa y Pupío en la Cuarta Región de Chile, Informe Técnico Final. OLCA. [Fecha de consulta: 11 junio 2014]. Disponible en: http://www.olca.cl/oca/chile/region04/mlp/olca_mlp/informes/informes_pdf/ tecnico_final.pdf 
Santos, M. (2013), Por uma outra globalização. Do pensamento único à consciencia universal, Editora Record, Rio de Janeiro, Brasil.

Sohr, R. (2013), Así no podemos seguir. Política, energía y medioambiente, Ramdon House Mondadori, Santiago, Chile

Sohr, R. (2012), Chile a ciegas. La triste realidad de nuestro modelo energético. Ramdon House Mondadori, Santiago, Chile

Solimano, A. (2012), Capitalismo a la chilena. Y la prosperidad de las élites, Catalonia, Santiago, Chile.

Svampa, M. (2012), “Consenso de los commodites, giro territorial y pensamiento crítico en América Latina”. Observatorio Social de América Latina (OSAL). Año XIII (32); p. 16-38, noviembre. ISSN 1515-3282. Disponible en: http://biblioteca.clacso.edu.ar/clacso/osal/20120927103642/ OSAL32.pdf

Ídem (2011), “Modelos de desarrollo, cuestión ambiental y giro ecoterritorial”. En AlimondA, H. (Coordinador). La naturaleza colonizada. Ecología política y minería en América Latina, p. 181-215,CLACSO-Ediciones CICCUS. Buenos Aires, Argentina.,.

Svampa, M; Bottaro, L; Sola Álvarez, M. (2009), “La problemática de la minería metalífera a cielo abierto: modelo de desarrollo, territorio y discursos dominantes”. En Svampa, M; Antonelli, M. (Editoras). Minería transnacional, narrativas del desarrollo y resistencias sociales, p. 29-46, Editorial Biblos, Buenos Aires, Argentina.

Svampa, M. (2008), “La disputa por el desarrollo: territorio, movimientos de carácter socio-ambiental y discursos dominantes”. En Svampa, M. Cambio de época. Movimientos sociales y poder político, Siglo XXI/CLACSO, Buenos Aires, Argentina..

Tanuro, D. (2014), “ Las fases del desarrollo de la crisis ecológica capitalista”. Sin Permiso. Septiembre 2013. [Fecha de consulta: 11 junio 2014]. Disponible en: http://www.sinpermiso.info/articulos/ficheros/tanuro.pdf

Tetreault, D. (2008), “Escuelas de pensamiento ecológico en las ciencias sociales”. Estudios Sociales 16 (32): 1-36, julio-diciembre.

Tobío, O. (2012), Territorios de la incertidumbre. Apuntes para una geografía social, UNSAM Edita, Buenos Aires, Argentina.

Toledo, V.; Barrera-Bassols, N. (2008), La memoria biocultural. La importancia ecológica de las sabidurías tradicionales, Icaria, Barcelona, España.

Yañez, N.; Molina, R. (2011), Las aguas indígenas en Chile, LOM Santiago, Chile. 


\section{Linkografía}

Coalición ciudadana por Aysén Reserva de vida http://aysenreservadevida.blogspot.com/

Ecosistemas

http://www.ecosistemas.cl/web/

Observatorio Latinoamericano de Conflictos Ambientales http://olca.cl/oca/index.htm

Patagonia chilena sin represas

http://www.patagoniasinrepresas.cl

Revista Que Pasa

http://www.quepasa.cl/

Recibido: 15.09.2014

Aceptado: 20.03.2015 